\title{
COMPETENCIAS, RASGOS, PRINCIPIOS Y REGLAS DE LA ÉTICA PROFESIONAL
}

\author{
Ana Cecilia Hirsch Adler *
}

\section{RESUMEN}

La parte sustancial del marco teórico del Proyecto de Investigación sobre Ética Profesional, que se lleva a cabo en la Universidad Nacional Autónoma de México (UNAM), se refiere a principios y reglas de la ética profesional. Además de presentar ese tema, se incluye un breve apartado sobre qué son las competencias, cuáles se tomaron en cuenta en el proyecto de investigación y que rasgos se integraron a partir del trabajo de campo.

\section{ABSTRACT}

The substantial part of the theoretical frame of the Project of Investigation on Professional Ethics, carried out in the National University of Mexico (UNAM), talks about principles and rules of professional Ethics. Besides presenting the topic, it includes a brief section on what are the competences, which were taken into account in the investigation project and the characteristics integrated from the work field.

* Licenciatura en Sociología. Facultad de Ciencias Políticas y Sociales - UNAM. Posgrado: "Programa de capacitación para la investigación educativa y la formación de profesores universitarios en ciencias y técnicas de la educación", Centro de Investigaciones y Servicios Educativos - UNAM. Maestría en Sociología. Facultad de Ciencias Políticas y Sociales

- UNAM. Doctorado en Sociología. Facultad de Ciencias Políticas y Sociales UNAM. Instituto de Investigaciones sobre la Universidad y la Educación, UNAM. hirsch@servidor.unam.mx 


\section{El proyecto de investigación sobre ética profesional}

En la mayoría de las universidades y carreras, hay una orientación prioritaria hacia la formación científica y técnica, dejando de lado la prepa- ración de los estudiantes en torno a la ética profesional. Esta situación puede ser causa de algunos problemas educativos y profesionales im- portantes. Es por ello que la UNAM aprobó un proyecto de investigación acerca de la ética profesional, con respecto a los alumnos y profesores de posgrado.

El proyecto cuenta con dos fases.

En la primera, ya terminada, con estudiantes, se realizaron cinco tipos de actividades interrelacionadas: ) Construcción del marco teórico, 2) Entrevistas a once profesores universitarios españoles, 3) Construcción y actualización de un estado de conocimiento sobre valores profesionales en México, 4) Construcción de una Escala de Actitudes sobre Ética Profesional y 5) Aplicación de la Escala a dos muestras de grupos de estudiantes de maestría y doctorado, uno en la Universidad de Valencia en España y otra en los 40 posgrados de la UNAM.

En la segunda fase, se aplicó la Escala de Actitudes sobre Ética Profesional a una muestra de profesores de los 40 programas de posgrado de la UNAM. El instrumento es el mismo y sólo se agregaron nuevas preguntas abiertas acerca de valores universitarios y profesionales, la importancia de la ética profesional y que contenidos debería contener para su enseñanza.

También en el 2006, se organizó el Proyecto Interuniversitario sobre Ética Profesional, entre la UNAM y otras 4 universidades del país. Los equipos están utilizando la misma estrategia metodológica para encuestar simultáneamente a estudiantes y profesores de posgrado. 


\section{Competencias y rasgos}

¿¿Qué son las competencias? Para Antonio Bernal (2004: 42):

Las competencias pueden concebirse como acciones intencionales y se refieren no únicamente a las tareas 0 habilidades que se ejecutan, sino también a la comprensión de las situaciones problemáticas que los sujetos han de afrontar; por otra parte, aunque las competencias puedan manifestarse focalmente en la ejecución de ciertas tareas específicas, presentan un carácter general fundado en su relación con la personalidad del sujeto.

Presupone otorgar un claro valor a la intencionalidad del sujeto. Tiene un carácter relacional pues vinculan cuestiones de la personalidad del sujeto a ciertas tareas o grupos de tareas. Están relacionadas con la puesta en práctica integrada de aptitudes y rasgos de la personalidad y con los conocimientos adquiridos.

El autor afirma que podemos identificar rasgos de las competencias. Ese conjunto de rasgos constituye "una especie de yo competente, en- cargado de la organización y mediación de conductas a través de un amplio repertorio de tareas y de roles, configurador de la identidad personal".

Antonio Bolívar (2005: 98), retoma de Michel Eraut la distinción entre competencia como concepto situado socialmente (habilidad para realizar tareas y roles de acuerdo con los estándares esperados) y como concepto situado individualmente (conjunto de capacidades o características personales requeridas en un trabajo o situación). Al primero lo denomina competencias, "por el lugar central que ocupan los criterios efectivos en cada profesión en relación con las demandas de los clientes" y al segundo capacidades, "como aptitudes que una persona tiene para pensar o hacer". 
Son una estructura cognitiva y cubren un amplio espectro de habilidades para funcionar en situaciones problemáticas, lo que supone conocimiento, actitudes, pensamiento metacognitivo y estratégico. "Designan la capacidad o facultad para movilizar diversos recursos cognitivos (saberes, capacidades, informaciones, etc.) en orden a actuar, con pertinencia y eficacia, en un conjunto de situaciones" (Bolívar, 2005: 98).

2. Competencias y rasgos del Proyecto de Investigación sobre Ética Profesional.

Como ya se mencionó previamente, una de las actividades sustantivas de la investigación fue la construcción de una Escala de Actitudes sobre Ética Profesional.

El instrumento se diseñó de la siguiente manera:

a) Se formuló la pregunta abierta ¿Cuáles son los principales rasgos de ser "un buen profesional"?, que resultó ser una pregunta detonadora de múltiples respuestas.

b) Se aplicó a una muestra en la Ciudad de Valencia.

c) Con las respuestas (y el número de veces en que mencionaron), se obtuvieron rasgos básicos.

d) Se clasificaron en cinco tipos de competencias: cognitivas, técnicas, éticas, sociales y afectivo - emocionales.

e) Los rasgos fueron analizados por 0 jueces.

f) Se construyó una escala para la prueba piloto, que se aplicó a una muestra de estudiantes de posgrado, profesores universitarios y profesionales.

g) Los resultados se capturaron en el Programa SPSS para obtener la coherencia de la escala y la validez de cada proposición.

h) Se hizo una revisión cuantitativa y cualitativa del instrumento y con ella se diseñó el instrumento final (con 55 proposiciones). 
En la UNAM se aplicó en el mismo instrumento la pregunta abierta y la Escala y se conservó la clasificación en competencias (se unificaron las cognitivas y técnicas) y sus respectivos rasgos. Se mencionan a continuación:

I. Competencias cognitivas y técnicas. Incluyen los siguientes rasgos:

a) Conocimiento, formación, preparación y competencia profesional.

b) Formación Continua.

c) Innovación y superación. d) Competencias técnicas.

II. Competencias sociales. Se trata de:

a) Compañerismo y relaciones. b) Comunicación.

c) Saber trabajar en equipo. d) Ser trabajador.

III. Competencias éticas:

a) Responsabilidad. b) Honestidad.

c) Ética profesional y personal.

d) Prestar el mejor servicio a la sociedad. e) Respeto.

f) Actuar con principios morales y valores profesionales. IV.

Competencias afectivo - emocionales:

a) Identificación con la profesión. b) Capacidad emocional.

La selección de los tipos de competencias y de sus rasgos se produjo, pues, con base en el trabajo de campo. 


\section{Principios y reglas de la ética profesional}

Los principios y reglas de la ética profesional provienen originalmente de la Bioética y de las Ciencias Biomédicas. Aunque sus antecedentes son muy antiguos, su principal desarrollo se produce al finalizar la Segunda Guerra Mundial. Por su relevancia, han permeado la reflexión en todas las áreas del conocimiento.

Diferencias entre principios y reglas de la ética profesional

Sólo hay distinción, de nivel de abstracción y generalidad, entre los principios y las normas. La diferencia es que las reglas son más específicas en su contenido y más restringidas en alcance que los principios. Estos últimos son normas generales que dejan amplio espacio para juzgar en muchos casos. Por tanto, no funcionan como guías precisas de acción que nos informen, en cada circunstancia, como actuar en sentido más detallado, como es el caso de las primeras.

Principios de la ética profesional

Para Beauchamp y Childress (200 : -25), un conjunto de principios en el ámbito moral deberían funcionar como un marco de referencia analítico, que exprese los valores generales que subyacen a las reglas de la moralidad común.

Para Augusto Hortal (2002), cada ética profesional genera, en su propio ámbito, una clasificación de situaciones, asuntos, conflictos y modos de abordarlos y resolverlos, que permiten analizar lo que está en juego en la toma de decisiones. Los nuevos casos son juzgados, en primera instancia, con base en los elementos conocidos.

Los principios son imperativos de tipo general, que orientan acerca de lo que es bueno hacer y lo que debe evitarse. Señalan grandes temas y valores de referencia, que hay que tomar en cuenta a la hora de decidir y de enfrentar casos problemáticos. 
Para este autor, los principios pueden ser el punto de partida o de llegada de una actuación: el "razonamiento moral descendente" va de los principios generales a otros más específicos, paulatinamente, hasta llegar a las decisiones singulares. Para poder ser aplicados, deben ser revisados e interpretados con respecto al contexto en que se producen y a las situaciones y casos que se busca resolver. El "razonamiento moral ascendente" parte de las actuaciones y decisiones singulares en situaciones concretas. De ahí se van generando criterios de actuación, hasta llegar al nivel más general de los principios. Ambos procesos se combinan.

En la ética profesional, de acuerdo con Beuchamp y Childress (200 ) están implícitos cuatro principios: Beneficencia, No Maleficencia, Auto- nomía y Justicia. Se presentan a continuación.

\section{Beneficencia}

La palabra beneficencia está compuesta de dos vocablos de ori- gen latino, bene y facere, que podrían traducirse como hacer el bien. Hace referencia a la consecución de determinados bienes específicos de la práctica profesional correspondiente (Berme- jo, 2002:75).

Este principio implica todas las formas de acción profesional que bus- can beneficiar a otras personas.

Cada profesión se plantea y legitima frente a los demás, la consecución de ciertos bienes y servicios. Para ser buenos profesionales, los individuos deben conocerlos y buscar su cumplimiento, tanto con respecto a los beneficiarios que reclaman un trabajo bien hecho, como de la sociedad en su conjunto, que pretende resolver problemas prioritarios con la contribución de los profesionales (Bermejo, 2002). 
En este campo de investigación, lo primero que hay que plantearse es la finalidad de cada profesión. Se puede partir de responder preguntas básicas como son: ¿Qué bienes y/o servicios produce?, ¿Para quién? y

¿De qué manera?

En la evaluación de los profesionales, se consideran no sólo los directamente beneficiados por su actividad, sino también los individuos y grupos que se relacionan con las acciones desarrolladas. Así, podemos referirnos a beneficiarios directos e indirectos (o terceras personas).

La ideología del profesionalismo (Freidson 2003) enfatiza el uso del conocimiento y habilidades disciplinarias para el bien público. Aunque algunas disciplinas proporcionan directamente un bien específico a personas, grupos e instituciones, los bienes y servicios que se generan son siempre valorados con respecto a un bien común más amplio. Los profesionales y sus asociaciones tienen la obligación de valorar lo que hacen con esa perspectiva. Es evidente que para ello se requiere competencia profesional, que se adquiere por una formación inicial y que se actualiza continuamente y que se basa, fundamentalmente, en conocimientos y habilidades, de carácter teórico y práctico.

Augusto Hortal (2002) retoma de Alasdair Maclntyre la distinción entre bienes intrínsecos y extrínsecos. Los primeros están ligados a la adecuada realización de la práctica profesional y los segundos se refieren a las recompensas económicas, de poder y de prestigio que se asocian a ella. Es evidente que los bienes intrínsecos son los prioritarios y que se tergiversan las actividades profesionales cuando los esfuerzos están dirigidos únicamente al logro de beneficios personales. 
Freidson (2003) considera que existe una larga tradición de estudiosos que defienden que los profesionales buscan el bien del cliente, del público o el desarrollo de una profesión, por encima de su propio interés económico. Afirma, que no puede haber una justificación ética para los profesionales que sólo buscan el beneficio personal, por sobre la obligación de hacer un buen trabajo para el que lo necesite. El fortalecimiento de la legitimidad del profesionalismo requiere un claro reconocimiento de las implicaciones éticas del privilegio profesional y una fuerte resistencia a los acuerdos institucionales que enfatizan exclusivamente los incentivos económicos.

Aunque el principio de Beneficencia se plantea en general para todas las profesiones, es importante pensar en las diferencias que se producen entre ellas. Así, para cierto tipo de ciencias, como las exactas y naturales, podremos encontrar más fácilmente la reflexión sobre la ética profesional en la ética de la ciencia y de la investigación científica, mientras que en otro tipo de disciplinas, como las sociales y humanísticas y principalmente en aquellas que tienen una eminente labor asistencial, la relación directa con los beneficiarios de la actividad profesional ocupa un lugar preponderante. Esto no exime, por supuesto, a ninguna profesión de la evaluación de las consecuencias que se producen por la toma de decisiones y por el uso que se hace de sus resultados.

No Maleficencia

El Principio de No Maleficencia enfatiza la obligación de no infligir daño a otros: "Por sobre todo no hacer daño". Consiste en actuar de manera que no se ponga en riesgo o se lastime a las personas.

El evitar el daño a los hombres y a la naturaleza, se vuelve muy importante, especialmente, en el caso de las ciencias y la tecnología, que cuando se utilizan inadecuadamente tienen un enorme potencial destructivo. Para la inmensa mayoría de las personas, la ética de las ciencias se centra en la preocupación por los peligros del uso de la ciencia y la tecnología (no de éstas en sí) y por los límites que conviene establecer. 
Este principio sostiene reglas morales específicas, como son: no matar, no causar pena o sufrimiento, no causar incapacidad, no causar ofensas y no privar a otros de los bienes de la vida.

\section{Autonomía}

La palabra autonomía procede del griego: autos (sí mismo) y nomos (ley) y hace referencia a la capacidad que tiene cada cual de darse a sí mismo sus propias normas, procurando construir la propia vida a partir de ellas. (Beuchamp y Chi- dress, 200 :57- 2 y Bermejo, 2002: 05)

En este segundo principio hay dos acepciones. Una de ellas se centra en el profesional, que requiere independencia y libertad para poder realizar adecuada y éticamente su trabajo y la otra se centra en el beneficiario, que posee derechos que deben ser respetados. Ambas posturas (que son complementarias) se plantean a continuación:

\section{Autonomía del profesional}

Se refiere a la capacidad personal de tomar decisiones en el ejercicio de la profesión. Tiene que ver con estar libre de interferencias de control por parte de otros y de contar con un entendimiento adecuado para tomar decisiones significativas (capacidad para la acción intencionada). Por ello, se condena la presión externa (extraprofesional), tanto de individuos, como de instituciones públicas y privadas en la toma de decisiones relevantes.

Lo más importante de la ideología profesional (Freidson 2003) es que está vinculada a valores trascendentes que le dan sentido y justifican su independencia. Los profesionales reclaman el derecho de evaluar las peticiones de empleadores o patrones y las leyes del Estado. Su revisión está basada en razones profesionales, que llevan a la convic- ción de que se está tergiversando el valor o propósito fundamental de una profesión. Los profesionales tienen que ser capaces de equilibrar el bien público con las necesidades más inmediatas de los clientes y empleadores. 


\section{Autonomía del beneficiario}

En el segundo caso, el principio de autonomía busca corregir la falta de simetría entre quien ofrece el servicio y el beneficiario de la actividad.

El profesional por su preparación, acreditación y dedicación tiene un ascendente sobre sus clientes y usuarios. La desigualdad entre ambas partes puede producir abusos (entre ellos el paternalismo). Para evitarlos, es necesario que esté siempre en funcionamiento el principio de autonomía. Consiste en considerar que el receptor de los servicios (individual y colectivo) no es un ente pasivo, sino un sujeto protagonista. De ahí se deriva la obligación de garantizar a todos los individuos involucrados, el derecho de ser informados, de que se respeten sus derechos y de consentir antes de que se tomen decisiones con respecto a ellos; protegiendo de manera especial a los que no pueden decidir por sí mismos.

Cuando se toma en cuenta este principio, se establece una relación de carácter profesional, en la que se desarrollan ciertos acuerdos y estrategias conjuntas entre los profesionales y sus beneficiarios. En el caso de la universidad, por ejemplo, es necesario reconocer que los estudiantes pueden ejercer por sí mismos su autonomía, en plenitud de derechos, capacidades y responsabilidades.

Existen ciertos requisitos para que pueda darse una decisión autónoma (Bermejo, 2002). Son de dos tipos, los de carácter social y cultural, que implican que el contexto debe contar con condiciones propicias para ello y los de carácter personal, es decir, que los beneficiarios de la actividad profesional actúen con iniciativa y capacidad.

Sintetiza los requisitos en "querer", "saber" y "poder". En el primero, los destinatarios deben contar con motivación para demandar al profesional el tipo de bienes y servicios que requieren. 
En el segundo, requieren de información, que incluye conocer otras opciones disponibles y las consecuencias que acarrea cada una de ellas. El tercero implica que sí se quiere algo y se sabe cómo realizarlo, es necesario poder llevarlo a cabo. En todo proceso de decisión, el papel del profesional es apoyar, mediante sus recursos profesionales, la competencia e información de los beneficiarios.

Beauchamp y Childress (200 ) consideran que las acciones pueden ser autónomas en cuestión de grado y plantean un continuum sobre la autonomía: desde estar totalmente presente hasta estar completamente ausente.

En algunas situaciones el principio de autonomía puede restringirse (Bermejo, 2002), aunque la decisión debe hacerla el profesional en cada caso. Los límites pueden suscitarse cuando: el beneficiario no tiene la competencia o los recursos personales para decidir, puede producirse un daño grave a terceras personas, la conducta del usuario supone una infracción de la legalidad o una grave amenaza para las personas y las instituciones, y las persona se perjudica a sí mismo o sus decisiones no le benefician.

Consentimiento Informado

Desde los juicios de Nürenberg (a finales de la década de los años cuarenta), en donde se pusieron en evidencia los horribles casos de experimentos con humanos por parte de los Nazis, el consentimiento se convirtió en la parte central de la ética biomédica. El término en sí, no apareció hasta una década después y no fue analizado con profundidad hasta principios de los setenta. En los años recientes, el interés se ha ampliado de la obligación del médico y del investigador en transparentar la información hacia la posibilidad del paciente y sujeto de investigación para entenderla y otorgar su consentimiento. La principal justificación consiste en proteger la elección autónoma. 
El hecho de que existan formas variadas de consentimiento lleva a la interrogante sobre: ¿Quién debe buscar qué tipo de consentimiento de quién y para qué?

El profesional debe obtener la autorización del usuario (individual y colectivo) para iniciar con él cualquier tipo de intervención, después de haberle explicado con claridad todas las condiciones (Bermejo, 2002). Incluye tres criterios básicos: conocimiento, voluntad y competencia.

Hay circunstancias que producen excepciones. Estas son: falta de responsabilidad de los beneficiarios, posibles daños a terceros y limitaciones derivadas de la incapacidad (por dificultades de comprensión y madurez, falta de capacidad o falta de libertad).

Justicia

La ética profesional queda incompleta si no se enmarca en la perspectiva de una ética social, que permita entender en qué contribuye o puede contribuir el trabajo de cada profesión a mejorar la sociedad. Las preguntas básicas son: ¿Qué es lo justo?, y ¿qué es prioritario cuando no hay recursos para satisfacer las demandas de todos?

Un buen profesional tiene, o debería tener, siempre presente el contexto social de referencia y las obligaciones de justicia. La ética profesional permite reflexionar sobre si la función social que desempeña una profesión es la misma que la que la sociedad necesita de ella.

Con el principio de justicia (Bermejo, 2002) se hacen presenten tres protagonistas: los usuarios que reclaman determinados bienes y servicios, el profesional que requiere de medios para ofrecerlos y los responsables públicos; que representan al conjunto de la sociedad y buscan con- seguir un cierto equilibrio entre necesidades, exigencias y expectativas de todos.

Freidson (2003) considera que sería apropiado declarar como profesionalmente inmorales las políticas sociales que nieguen un acceso igualitario a servicios de salud, educación y defensa jurídica. Afirma que deben ser juzgadas las instituciones en que ejercen profesionales que no cuentan con las condiciones de trabajo necesarias para realizar un correcto ejercicio. También es necesario cuando las instituciones sólo buscan maximizar sus ganancias, a costa de la calidad del trabajo y de limitar aún más la distribución de los beneficios.

Para Beuchamp y Childress (200 :225-282), el Principio de Justicia implica rectitud, equidad y apropiada distribución de los recursos y beneficios, con respecto a lo que se debe o merecen las personas, a través de normas justificadas que se 
basan en la cooperación social. Tiene que ver con las políticas que distribuyen diversas cargas y beneficios, tales como: propiedades, recursos, impuestos, privilegios y oportunidades.

Principales reglas de la ética profesional

Las reglas sustantivas más relevantes son: veracidad, privacidad, confidencialidad y fidelidad.

\section{Veracidad}

Cuando se entabla la relación: profesional - beneficiario, se establece un acuerdo implícito de que la comunicación se basará en la verdad. Se refiere a una completa, correcta y objetiva transmisión de información, así como al modo en que el profesional promueve su comprensión en el sujeto. Hay tres argumentos que contribuyen a su justificación (Beauchamp y Childress, $200: 284$ ): respeto a los otros, su conexión a la fidelidad (cumplimiento de las promesas y acuerdos) y confianza. Cumplir con la reglas de veracidad es esencial para promover la confianza.

\section{Privacidad}

El derecho a la privacidad (Beauchamp y Childress, 200 :294) se refiere al acceso limitado a las personas, en cuestiones físicas y de información y a la libertad de decisión. Hay cinco formas de privacidad: en la información, física, de las decisiones, en la propiedad y en las relaciones, que incluye a la familia y las relaciones íntimas. Implica que las decisiones no necesariamente son individuales, sino que involucran a otros (son singulares o conjuntas).

\section{Confidencialidad}

Es el derecho que tiene cada persona de controlar la información referente a sí misma, cuando la comunica bajo la promesa -explícita o implícita- de que será mantenida en secreto. Se refiere a un criterio general de conducta que obliga al profesional a no discutir información acerca de los beneficiarios con otros. Obliga a guardar los secretos que uno conoce en razón del ejercicio profesional y a respetar la intimidad de las personas implicadas.

En la práctica hay situaciones en que el profesional puede verse obliga- do a revelar, sin el consentimiento de los beneficiarios de su actividad, alguno de los detalles recibidos confidencialmente (Bermejo, 2002). Estos casos buscan: beneficiar de algún modo al cliente o usuario, o protegerlo de algún mal que pudiera ocasionarse a sí mismo; proteger a terceros; poner en común ciertos datos con otros colegas y profesionales; y respetar la orden de alguna autoridad administrativa o judicial. El problema ético, en estos casos, radica en decidir acerca de la necesidad de contravenir la confidencialidad. De todos modos, las 
personas tienen derecho a que se le comunique, desde el inicio de la relación profesional, el tratamiento que se va a dar a la información, la obligatoriedad de la confidencialidad en general y las excepciones que pueden generarse.

\section{Fidelidad}

El profesional hace promesas justas y cumple con sus acuerdos a aquellos a quienes presta el servicio. Es un derecho del cliente o usuario, elegir al profesional; y es un derecho de este último, aceptar o no la relación. Pero cuando ambas partes deciden iniciarla, se entabla un acuerdo sobre la base de las expectativas previamente conocidas o formuladas. Los códigos conceden que hay una promesa explícita de cumplir el acuerdo.

\section{CONCLUSIONES}

Como puede verse, el tema de los principios y reglas de la ética profesional, es un asunto ineludible en la investigación en este campo te- mático. Son un punto de referencia, con los cuales se puede contrastar el comportamiento de los profesionales en sus lugares de trabajo y un elemento básico en la formación de los profesores y estudiantes universitarios. Se vincula fuertemente con el importante papel social que tienen las instituciones de educación superior. 


\section{FUENTES DE CONSULTA}

- BEAUCHAMP, T y Childress, J. (200 ), Principles of Biomedical Ethics. New York: Oxford University Press.

- BERNAL, Antonio (2003) "La construcción de la identidad personal como proyecto de educación moral. Supuestos teóricos y delimitación de competencias", en: Teoría de la Educación, Revista Interuniversitaria, España: Ediciones Universidad de Salamanca.

- BOLÍVAR, Antonio (2005) "El lugar de la ética profesional en la forma- ción universitaria", en: Revista Mexicana de Investigación Educativa, Vol. X, No. 24, enero - marzo, Consejo Mexicano de Investigación Educativa y Secretaría de Educación Pública.

- BERMEJO, Francisco (2002), La ética del trabajo socia. Bilbao: Desclée De Brouwer, S.A.

- FREIDSON, Eliot (2003) "El Alma del Profesionalismo", en: Sánchez, Ma- riano; Sáez, Juan y Svensson, Lennart. Sociología de las Profesiones. Pa- sado, Presente y Futuro, Murcia, España: Diego Marín Librero-Editor

- HORTAL, Augusto (2002), Ética General de las Profesiones. Bilbao: Des- clée De Brouwer, S. A.

- HIRSCH, Ana (2003) "Ética profesional como proyecto de investiga- ción", en: Teoría de la Educación. Revista Interuniversitaria, Vol. 5, Es- paña: Ediciones Universidad de Salamanca. 